\title{
Evaluation of serum pancreatic enzymes in type 2 diabetes mellitus and its correlation with insulin resistance
}

\author{
Jithesh.T.K ${ }^{1}$, Shifa. $\mathbf{K}^{2, *}$, Liji.K ${ }^{3}$, Anilamol.V.S ${ }^{4}$ \\ ${ }^{\mathbf{1 , 2}}$ Associate Professor, ${ }^{3}$ Assistant Professor, ${ }^{4}$ Medical Biochemist, Dept. of Biochemistry, ${ }^{\mathbf{1 , 2 , 3}}$ MES Medical \\ College, Perinthalmanna, Kerala, ${ }^{4}$ Maanu Scan Centre, Manjeri, Kerala, India
}

*Corresponding Author:

Email:kshifak@gmail.com

\begin{abstract}
Introduction: Type 2 diabetes mellitus is due to the decreased biological response to insulin or insulin resistance. Insulin resistance develops as a consequence of defects in signal transduction by insulin. These defects may also affect the exocrine pancreatic function. The aim of this study was to determine serum pancreatic enzyme levels in diabetic patients and to correlate them with insulin resistance.

Materials and Methods: In this case control study we compared fasting blood sugar, serum insulin, lipase and amylase levels and insulin resistance in diabetic and normal healthy adults. The correlation of pancreatic enzymes with insulin resistance was also studied.

Results: Diabetic group showed statistically significant increase in all the parameters compared to control group. Serum amylase showed a significant negative correlation with insulin resistance $(\mathrm{p}=0.007)$ and serum lipase a positive correlation with insulin resistance, but it was not significant $(\mathrm{p}=0.119)$.

Conclusion: The study showed a significant alteration in the exocrine pancreatic function in diabetic patients. There is a negative correlation between serum amylase level and insulin resistance.
\end{abstract}

Keywords: Amylase, Insulin Resistance, Islet-Acinar Axis, Lipase, Type 2 Diabetes Mellitus.

Received: $10^{\text {th }}$ May, 2017

\section{Introduction}

Pancreas is an organ with both exocrine and endocrine functions. Exocrine pancreas secretes digestive enzymes like amylase, lipase and trypsin while endocrine pancreas secretes hormones like insulin, glucagon and somatostatin. Pancreas has a complex structure with clusters of different endocrine cells dispersed within the exocrine acinar cells. ${ }^{1}$ This proximity of endocrine cells to the enzyme secreting acinar tissue lead to the postulation that islet hormones can influence the exocrine pancreatic function. $^{2}$

In Type 2 diabetes mellitus, there are defects in secretion and signaling of insulin. These defects may also affect the exocrine pancreatic activity. The endocrine-exocrine relationship in the pancreas has been evaluated in various animal studies. ${ }^{3}$ Previous studies showed that insulin affects exocrine pancreatic secretion via the islet-acinar axis. ${ }^{4-6}$ But the studies which evaluated the nature of this association between pancreatic enzymes and diabetes yielded some conflicting results. ${ }^{7}$

According to previous studies, an increased lipase activity positively correlated with increased level of blood glucose. Uncontrolled glucose levels can influence the level of triglyceride, and it will stimulate the lipase
Accepted: $07^{\text {th }}$ November, 2017

secretion to degrade triglyceride into free fatty acid. The elevated level of lipase activity is mainly seen in long standing diabetes. ${ }^{8}$

The aim of this study was to find out the relationship of serum amylase and lipase levels with insulin resistance in Type 2 diabetes mellitus.

\section{Materials and Methods}

This case control study was conducted in a tertiary care hospital in south India after obtaining approval from institutional ethics committee. A total of 32 diabetic patients who visited the hospital during October 15 to December 15, 2015 were enrolled into the study.

\section{Inclusion criteria}

1. Fasting blood glucose greater than or equal to $126 \mathrm{mg} / \mathrm{dl}$

2. A random blood glucose greater than or equal to $200 \mathrm{mg} / \mathrm{dl}$

Exclusion criteria:

1. Pregnant women

2. Individuals below 20 years

3. Chronic renal, hepatic, gastrointestinal, skeletal or endocrine diseases

4. Patients with autoimmune diseases

30 healthy age and sex matched adults were selected as controls. Informed consent obtained from all the subjects. General information was 
collected using questionnaire. Detailed clinical, epidemiological and anthropometric characteristics recorded. BMI calculated using the equation -weight $[\mathrm{kg}] / \mathrm{height}[\mathrm{m}] .^{2}$ All the subjects included in the study were in the age group of 31 to 70 years.

$5 \mathrm{ml}$ of fasting blood sample was collected intravenously and centrifuged for 10-15 minutes in a centrifuge. The separated serum was used for analysis of blood sugar, amylase, lipase, and insulin. Fasting blood sugar, lipid profile, serum amylase and serum lipase levels estimated by fully automated clinical chemistry analyzer (VITROS®5600 Integrated System). Serum insulin estimated by ELISA. Homeostasis model assessment of insulin resistance (HOMA-IR) was used for the measurement of insulin resistance and was calculated as follows:

Insulin resistance $=[$ fasting insulin $(\mu \mathrm{IU} / \mathrm{ml}) \mathrm{x}$ fasting glucose $(\mathrm{mg} / \mathrm{dl})] / 405$.

\section{Results}

The statistical analysis was done using SPSS 17. The values of each parameter were expressed as mean \pm SD. Serum amylase, lipase, insulin and insulin resistance showed a significant variation between test and control groups (Table 1) (Fig.1). All the parameters were higher in the test group. Even though, serum amylase and lipase levels fall within normal range, the values are on higher side.

Table 1: Statistical Representation of Evaluated Parameters for the Study

\begin{tabular}{|l|c|c|c|}
\hline \multicolumn{1}{|c|}{ Parameters } & Control $($ Mean \pm SD) & Test $($ Mean \pm SD) & P value \\
\hline BMI $\left(\mathrm{Kg} / \mathrm{m}^{2}\right)$ & $22.933 \pm 1.552$ & $26.25 \pm 4.103$ & $<0.001$ \\
\hline FBS $(\mathrm{mg} / \mathrm{dl})$ & $78.4 \pm 11.77$ & $197.6 \pm 65.01$ & $<0.001$ \\
\hline Serum Insulin $(\mu \mathrm{IU} / \mathrm{ml})$ & $5.453 \pm 0.388$ & $9.50 \pm 0.91$ & $<0.001$ \\
\hline Insulin resistance & $1.038 \pm 0.16$ & $4.55 \pm 1.66$ & $<0.001$ \\
\hline Serum amylase $(\mathrm{U} / \mathrm{L})$ & $29.94 \pm 2.47$ & $47.46 \pm 24.64$ & $<0.001$ \\
\hline Serum lipase $(\mathrm{U} / \mathrm{L})$ & $33.45 \pm 2.88$ & $68 \pm 34.37$ & $<0.001$ \\
\hline
\end{tabular}

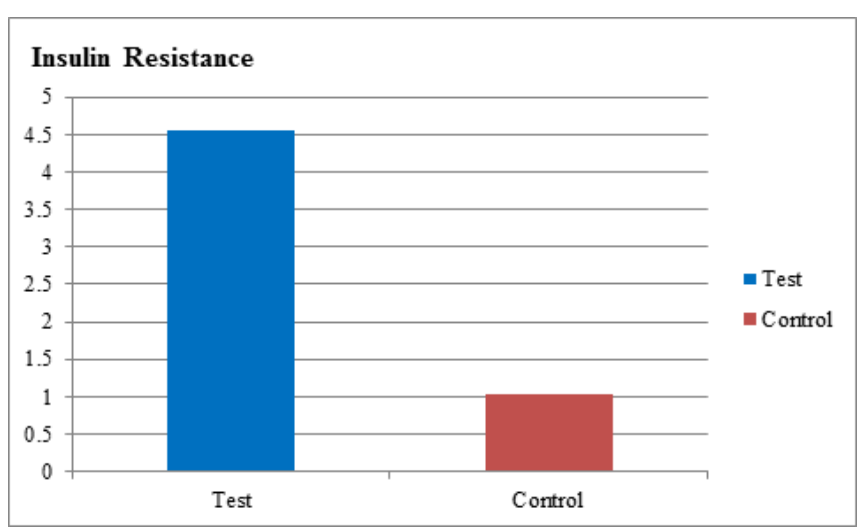

Fig. 1: Insulin resistance in Test and Control

Correlation between insulin resistance and pancreatic functions were studied. Serum amylase showed a significant negative correlation with insulin resistance $(\mathrm{p}=0.007)$. It was significant in case of males ( $\mathrm{p}=0.004)$, but, not in females $(\mathrm{p}=0.227)$ (Table 2) (Fig. 2)

Serum lipase has a positive correlation with insulin resistance, but it was not significant ( $p$ $=0.119$ ). Comparing the variation according to sex, males showed a positive correlation while females showed a negative correlation. But, both were not significant (Table2) (Fig. 3).

Table 2: Correlation between insulin resistance and pancreatic function

Table 2: Correlation between insulin resistance and pancreatic function
\begin{tabular}{|l|c|c|c|}
\hline Parameters & Mean \pm SD & R value & P value \\
\hline Amylase & $45.87 \pm 24.23$ & -0.55 & $0.007^{* *}$ \\
\hline Amylase $(\mathrm{M})$ & $41.95 \pm 23.84$ & -0.589 & $0.004^{* *}$ \\
\hline Amylase $(\mathrm{F})$ & $53.36 \pm 24.26$ & -0.396 & 0.227 \\
\hline Lipase & $68 \pm 34.3$ & 0.281 & 0.119 \\
\hline Lipase $(\mathrm{M})$ & $75.83 \pm 33.82$ & 0.311 & 0.169 \\
\hline Lipase(F) & $53 \pm 37.57$ & -0.009 & 0.97 \\
\hline
\end{tabular}

** Highly significant 


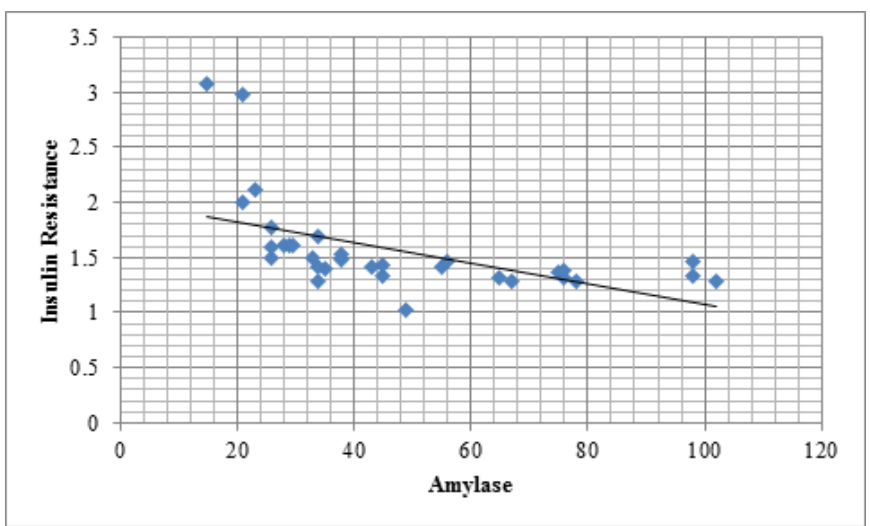

Fig. 2: Graphical representation of correlation between IR and Amylase

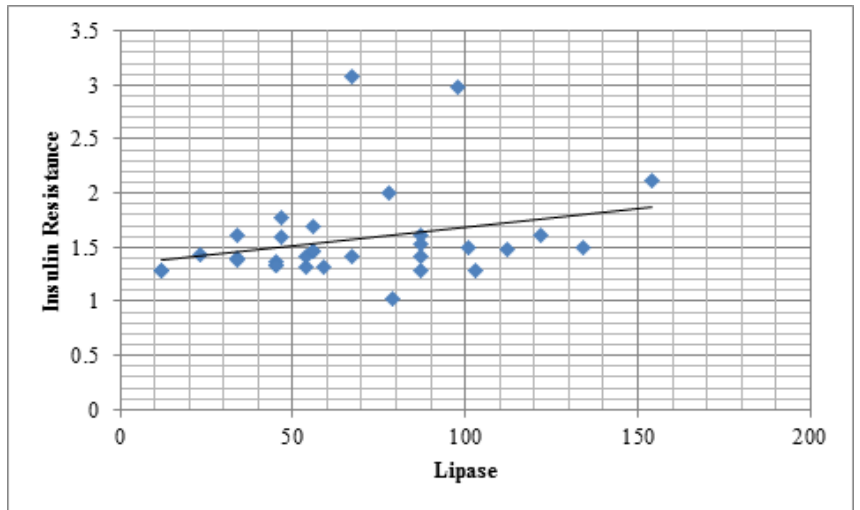

Fig. 3: Graphical representation of correlation between IR and Lipase

\section{Discussion}

The present study, investigated the levels of serum pancreatic lipase and amylase in type 2 diabetic patients compared to normal healthy individuals. It clearly shows an impairment of pancreatic enzyme activity and a significant correlation between low serum amylase level and insulin resistance. A probable explanation is that insulin resistance may lead to insulin inactivity by down regulating insulin receptor expression or reducing insulin signal transduction in various cells, including pancreatic acinar cells. This results in reduced insulinotropic action on the aci nar cells. ${ }^{9}$

An in vivo study conducted in the faculty of medicine, university of Jordan analyzed the biochemical effect of insulin therapy on enzyme activities in the pancreatic acinar cells of sreptozotocin - diabetic rats. They concluded that pancreatic amylase activities increase in diabetic rats. In this study, similar to our findings, lipase showed a positive correlation with insulin resistance, but it was not so significant $(\mathrm{p}=0.119) .{ }^{10}$

In another study, the correlation of serum lipase levels with duration and progression of disease in Type2 Diabetics of Indonesia were evaluated. The results suggest a high lipase activity in insulin resistance patients.

According to similar studies conducted in India, the serum amylase activity was significantly lower in the cases of type-2 DM $(n=110)$ as compared to that in the controls $(n=30)$ with a $p$ value of $<0.001$. This study also suggests a possible exocrine-endocrine relationship in diabetes. ${ }^{11}$

Another study conducted in Japan, investigated the correlation of reduced serum amylase with low plasma insulin levels and insulin resistance in asymptomatic adults. It was a cross-sectional study of 54 subjects measuring serum amylase, plasma insulin, leptin, cardio metabolic risk factors, and anthropometric parameters. These results show that low serum amylase is associated with decreased insulin levels and high insulin resistance after adjusting for BMI. ${ }^{12}$

\section{Limitations}

Small duration and small sample size were the limitations of our study. Any further study based on this topic shall be done by overcoming these limitations. 


\section{Conclusion}

The study showed a significant alteration in the exocrine pancreatic function with insulin resistance. High lipase and amylase concentrations were detected in patients with diabetes. But, there is a strong negative correlation between serum amylase and insulin resistance.

These findings need to be confirmed in further la rge studies.

\section{References}

1. Henderson JR, Daniel PM, Fraser PA. "The pancreas as a single organ: the influence of the endocrine upon the exocrine part of the gland"Gut(1981) 22,158-67.

2. Frier BM, Faber OK, Binder C, Elliot HL "The effect of residual insulin secretion on exocrine pancreatic function in juvenile-onset diabetesmellitus. Diabetologia(1978)14,301-4.

3. Aughsteen AA, Abu-Umair MS, Mahmoud SA "Biochemical analysis of serum pancreatic amylase and lipase enzymes in patients with type 1 and type 2 diabetes mellitus" Saudi Med J (2005) 26, 73-7.

4. Barreto SG, Carati CJ, Toouli J, Saccone GT "The islet-acinar axis of the pancreas: more than just insulin” Am J PhysiolGastrointest Liver Physiol(2010) 299, G10-22.

5. Kei Nakajima, ToshitakaMuneyuki, Hiromi Munakata and MasafumiKakei "Revisiting the cardiometabolic relevance of serum Amylase" BMC Research Notes (2011) 4,419.

6. Kanno T, Saito A "The potentiating influences of insulin on pancreozymin-induced hyperpolarization and amylase release in the pancreatic acinar cell" J Physiol(1976) 261,50521.

7. Trimble ER, Bruzzone R, Belin D“Insulin resistance is accompanied by impairment of amylase-gene expression in the exocrine pancreas of the obese"Zucker rat. Biochem J (1986) 237, 807-12.

8. Abbas E. Kitabchi, Guillermo E. Umpierrez, John M. Miles, Joseph N. Fisher "Hyperglycemic crises in adult patients with diabetes" Diabetes Care (2009 Jul) 32(7), 1335-43.

9. Mössner J, Logsdon CD, Goldfine ID, Williams J A“ Regulation of pancreatic acinar cell insulin rec eptors byinsulin"

Am J Physiol (1984) 247(2 Pt 1),G155-60.

10. Aughsteen AA Mohammed FI "insulin enhances amylase and lipase activity in the pancreas of sreptocin - diabetes rats - an invivo study"Soudi med. J (2002) 23(7),832-44.

11. Rakheeyadav,Jai prakashBartiya, Sunil kumarvarma and ManojkumarNandkeoliar " The evaluation of serum amylase in the patients of type $2 \mathrm{DM}$, with a possible correlation with the pancreatic function" Journal of clinical \& Diagnostic Research (2013 Jul) Vol-7(7),1291-4.

12. Muneyuki T, Nakajima K, Aoki A, Yoshidha M, Fuchigami H, Kwakami M, et al "Latent association of low serum amylase with decreased plasma insulin level and insulin resistance in asymptomatic middle aged adults"CardiovascDiabetol(2012 June) 29-11-180 doi 10-11-86/14-75-2840-11-80. 